\title{
Féeries
}

Études sur le conte merveilleux, XVII $-\mathrm{XIX}{ }^{\mathrm{e}}$ siècle

\section{La Belle et la Bête. Quatre métamorphoses} (1742-1779)

Textes établis et annotés par Sophie Allera et Denis Reynaud (Umr-LireLyon 2),Publications de l'université de Saint-Étienne, collection « Textes et Contre-Textes » $n^{\circ} 2,2002,212 p$.

\section{Anne Defrance}

\section{(2) OpenEdition}

12 Journals

\section{Édition électronique}

URL : http://journals.openedition.org/feeries/85

DOI : 10.4000/feeries.85

ISSN : 1957-7753

Éditeur

UGA Éditions/Université Grenoble Alpes

\section{Édition imprimée}

Date de publication : 1 février 2004

Pagination : 187-188

ISSN : 1766-2842

\section{Référence électronique}

Anne Defrance, «La Belle et la Bête. Quatre métamorphoses (1742-1779) », Féeries [En ligne], 1| 2004, mis en ligne le 29 janvier 2007, consulté le 21 septembre 2020. URL : http://journals.openedition.org/ feeries/85; DOI : https://doi.org/10.4000/feeries.85

Ce document a été généré automatiquement le 21 septembre 2020.

(C) Féeries 


\section{La Belle et la Bête. Quatre métamorphoses (1742-1779)}

Textes établis et annotés par Sophie Allera et Denis Reynaud (Umr-LireLyon 2),Publications de l'université de Saint-Étienne, collection « Textes et Contre-Textes $» \mathrm{n}^{\circ} 2,2002,212 \mathrm{p}$.

\section{Anne Defrance}

1 Laissant de côté le très long conte encastré dans le roman de Mme de Villeneuve publié en 1740 ( $L a$ Belle Amériquaine et les Contes marins), conte dont Jacques Cotin et Élizabeth Lemirre ont donné une édition séparée parue chez Gallimard en 1996, les auteurs ont choisi pour cette petite anthologie de retenir quatre textes parmi les diverses versions produites au XVIII ${ }^{e}$ siècle. Il s'agit du célèbre conte merveilleux écrit par Mme Leprince de Beaumont et de trois textes dramatiques, Amour pour Amour de Nivelle de la Chaussée (féerie créée en 1742), Zémire et Azor, opéra dont le livret est dû à Marmontel et la musique à Grétry (1771), et La Belle et la Bête, comédie de Mme de Genlis (1779).

Dans leur brève introduction, les auteurs rappellent l'origine populaire d'un conte dont des versions existent dans différents pays, conte répertorié par Aarne et Thompson (type 425 C) et qui inspira Rétif de la Bretonne (Les Quatre Belles et les Quatre Bêtes, 1778). Son origine lointaine et mythique est attestée par L'Âne d'or d'Apulée, qui narre les aventures du dieu Amour et de Psyché. Les auteurs laissent de côté la question des autres versions et des sources, entendant montrer avant tout que ce conte est « un conte des Lumières", qui "s'inscrit dans l'histoire des genres et des idées au XVIII siècle.» (p. 7). L'introduction renseigne ensuite sur la réception de ces différentes œuvres, fait état de quelques jugements critiques et souligne les différences essentielles entre les textes. Les auteurs évaluent l'écart qui sépare le "roman» de Mme de Villeneuve du petit conte de Mme de Beaumont, qu'ils refusent de considérer comme un simple résumé du premier, ainsi qu'il est parfois regardé.

Pour terminer, un aperçu de la fortune de ce mythe est offert : pour Sophie Allera et Denis Raynaud, les versions suivantes et avatars du thème, littéraires ou non, hésitent " entre les deux pôles que représentent Villeneuve et Marmontel, d'une part; Beaumont et Genlis d'autre part, [...] entre le goût baroque d'un spectacle étourdissant 
pour adultes, et la forme classique d'un récit moral pour enfants. » (p. 14). Enfin, il est question de l'illustration des textes: le xvIII évita de donner un corps à la Bête, les siècles suivants furent davantage imaginatifs (comme en atteste le livre de Betsy Hearne).

4 L'édition des textes est accompagnée de notes et de variantes. Le lecteur peut y trouver d'intéressantes références aux œuvres écrites par les prédécesseurs et les contemporains des auteurs, sous la forme de parallèles thématiques (Mme d'Aulnoy, Perrault, Marivaux, Crébillon, Rousseau, Rostand...), des informations sur les représentations et la distribution des pièces. Les auteurs y poursuivent en outre la comparaison entre les textes amorcée en introduction et fournissent des renseignements supplémentaires sur la réception et la critique (Fréron, Bettelheim...), ce qui permet d'enrichir la très brève bibliographie de sept titres. Le prix modique de ce livre devrait aider à sa diffusion auprès d'un large public, qui découvrira quelques textes peu connus, à côté du célèbre conte de Mme de Beaumont. Dans une perspective comparatiste, eu égard au but énoncé par les auteurs, on peut regretter que le conte fondateur de Mme de Villeneuve n'ait pas trouvé place ici, sans doute à cause de sa longueur, puisqu'il connaît aujourd'hui, tout comme celui de Mme de Beaumont, d'autres éditions. 